\title{
Issues of contemporary wind engineering and aerodynamics of building structures
}

\author{
Tomasz Lipecki, Paulina Jamińska
}

\begin{abstract}
Department of Structural Mechanics, Faculty of Civil Engineering and Architecture,
\end{abstract} Lublin University of Technology,e-mail: t.lipecki@pollub.pl,p.jaminska@pollub.pl

\begin{abstract}
The paper reviews nowadays problems and issues of wind engineering and aerodynamics of building structures. The article mainly focuses on aerodynamics of building structures, shortly characterizing theoretical bases, which one must take into account when assuming wind loads. The three different approaches of collecting information in the field of wind loads are described: in-situ measurements, wind tunnel tests and numerical simulations. Also, a review of the most important contemporary issues of wind engineering is presented.
\end{abstract}

Keywords: wind engineering, aerodynamics, wind tunnel, CFD, in-situ measurements.

\section{Introduction}

Wind loads became an object of special attention in the 60's and 70's of the XX century. This growing interest was mainly induced by a collapse of Tacoma Narrows Bridge and Ferrybridge Cooling Towers. The first event held in 1940 in US (Fig. 1a). The Tacoma Narrows Bridge - a suspension bridge of the large span and slender cross-section of the deck suffered vibrations caused by the wind action. The wind speed was not extremely high, but its action and uncommon structure of the bridge led to uncontrolled vibrations. It was one of the first documented collapses caused by so-called flexural-torsional flutter. The second disaster took place in 1965 in UK (Fig. 1b). The cluster compound of eight cooling towers of large dimensions stood one by one in very close distances. The acceleration of the flow between objects and vortices shedding from the windward cooling towers were not considered during the design process. Additional wind loads were produced, and it was the direct cause of the total collapse of the three cooling towers and of serious damages of the other five.

a)

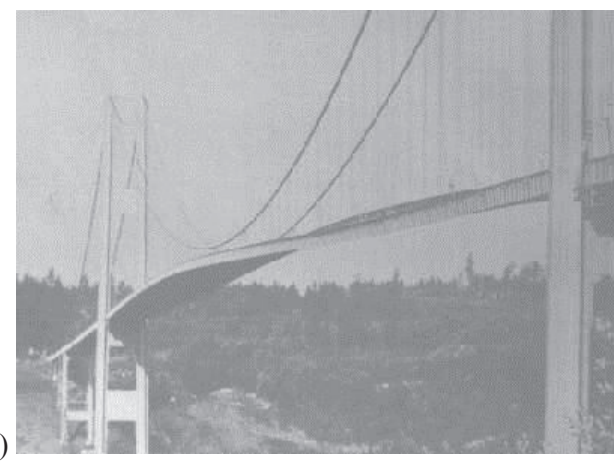

b)

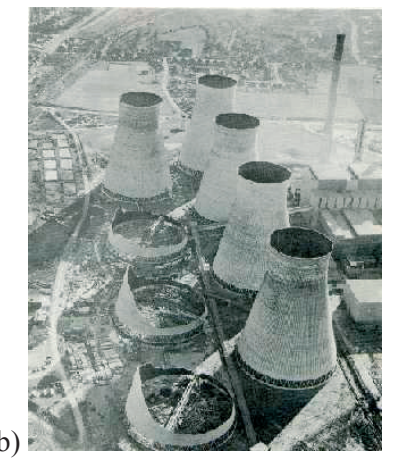

Fig. 1. Collapses of: a) Tacoma Narrows ((http://www.ketchum.org/bridgecollapse.html), b) cooling towers in Ferrybridge (http://www.knottingley.org/history/tales_and_events.htm\#Cooling\%20Towers) 
Moreover, serious large hurricanes, cyclones and tornadoes brought many fatalities and destroyed huge areas of land and land infrastructure.

All these aspects together gave rise to investigations in the field of wind engineering and structural aerodynamics.

Wind engineering is a wider concept than aerodynamics, and covers, among others, the following fields of science: meteorology, structural mechanics, wind energy, probability theory, statistics, fluid dynamics, theory of structural safety and reliability, wind hazards (risk evaluation), medicine (comfort/discomfort). The very detailed definition of the wind engineering as the multi-disciplinary science was given by Cermak (1975). In more general division, based on Cermak's definition, the main topics of wind engineering are: winds and their characteristic in the atmospheric boundary layer (atmospheric circulation, wind types, structure of strong winds, extreme winds, topography and orography influences on wind structure), aerodynamics of buildings and structures (wind actions on structures, windstructure interactions, aeroelastic phenomena, aerodynamic interference, wind and rain induced vibrations, structural response to wind actions safety and reliability of structures, damping), wind influence on people (pedestrians comfort, comfort of people in buildings, human reactions to wind-induced vibrations), environmental effects of wind (pollutant dispersion, sand or snow transport, waves on seas), wind power (wind farms and wind turbines), natural disasters (extreme winds risk assessment, damage reduction), normalization (regulations, standards, codes, design guidelines).

This paper presents frames of the basic knowledge which engineers must have to responsibly assume wind actions on structures. Next, the presentation of three experimental methods allowing to gather data about wind actions, with examples of their applications, is enclosed. Contemporary problems faced by wind engineering are described at the end of the paper.

\section{Base knowledge}

\subsection{Wind structure in atmospheric boundary layer (ABL)}

The atmospheric boundary layer can be distinguish close to the Earth's surface. The structure of the wind in the ABL - the space, time and frequency characteristics of the wind speed - must be determined. Wind speed is a stochastic function of time and space, and can be expressed as the sum of the mean value $-\bar{U}$ (characterizing the static action) and fluctuation around the mean $-\mathrm{U}^{\prime}$ (characterizing the dynamic action), according to the equation:

$$
U_{i}(x, y, z, t)=\bar{U}_{i}(x, y, z)+U_{i}^{\prime}(x, y, z, t)
$$

where: $i=x, y, z$ are respectively: horizontal component along the mean wind direction, second horizontal component perpendicular to the first one, and vertical component, $t$ is time. The respective vector components of the wind speed can be alternatively described by letters: $u, v$ and $w$. Every component is also the sum of the mean value and fluctuation:

$$
\begin{aligned}
& u(x, y, z, t)=\bar{u}(x, y, z)+u^{\prime}(x, y, z, t) \\
& v(x, y, z, t)=\bar{v}(x, y, z)+v^{\prime}(x, y, z, t) \\
& w(x, y, z, t)=\bar{w}(x, y, z)+w^{\prime}(x, y, z, t)
\end{aligned}
$$

To describe wind speed, it is necessary to determine mean speed, and its changes along the height. In the ABL the vertical changes of the mean wind speed take place. 
The speed increases with the height above the ground, until it reaches the gradient wind speed $U_{\text {grad }}$, at the height $z_{\text {grad }}$. The variation of the mean wind speed with height can be expressed using mathematical formulas known as vertical wind profiles. There are two groups of formulas describing the wind speed profile: theoretically developed logarithmic equation (log-law profile) and power-law equation. The best known and firstly defined (by Alan Davenport), is the power-law formula, which illustrate wind speed changes over different terrain types (Davenport, 1960, 1965). The original values and formula given by Davenport are presented in Fig. 2, whereas profiles recommended by Eurocode (2008) are shown in Fig. 3a.

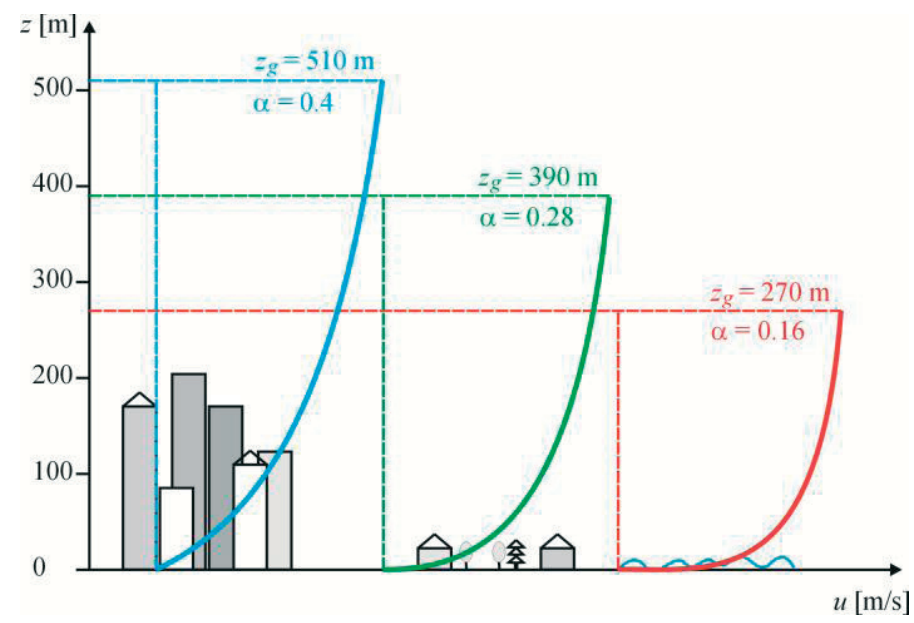

$$
\bar{U}(z)=U_{\text {grad }}\left(\frac{z}{z_{\text {grad }}}\right)^{\alpha}
$$

Fig. 2. Wind profiles defined by Davenport over different terrains

Turbulent character of wind must be defined if a wind action is considered. The following characteristics of the fluctuating part (turbulence) should be given: intensity and scales of turbulence, peak factors, the correlation functions (in the time domain) and power spectral density functions (in the frequency domain). Intensity of turbulence, in general, defines time changes of the wind speed around the mean value. Turbulence length scale is a measure of the size of gusts of the wind speed in space and represents the distance in which the process is correlated. Examples of that functions are presented in Fig. 3b, c. Correlation functions give the detailed description of the wind structure, as a space-time stochastic process in the time domain. On the basis of correlation functions one can get additional information of the wind structure in the frequency domain. Applying Fourier transforms to respective correlations we can get power spectral density functions (PSD). There are several practical PSD functions in wind engineering elaborated on the basis of local measurements. An example of PSD function is presented in Fig. 4.

Characteristics of the wind speed can be described differently depending on civil engineering standards and codes which consider wind actions on structures. Among the most important standards in this field are: 1) Eurocode 1. Actions on structures - Part 1-4: General actions - wind actions. 2) ASCE - American Society of Civil Engineers. Minimum design loads for buildings and other structures. 3) AS/NZS - Structural design actions Part 2: Wind actions. Australian/New Zealand Standard. 4) AIJ - Architectural Institute of Japan. RLB recommendations for loads on buildings. Tokyo, Japan. 5) CNS - Load code for the design of building structures, China National Standard. 7) ISO - ISO. 4354. Wind 
actions on structures. Switzerland: International Organization for Standardization. 7) ESDU - Engineering Science Data Unit (this is not a code, but it contains many calculation procedures developed on the basis of in-situ and model measurements, it consists of several items).
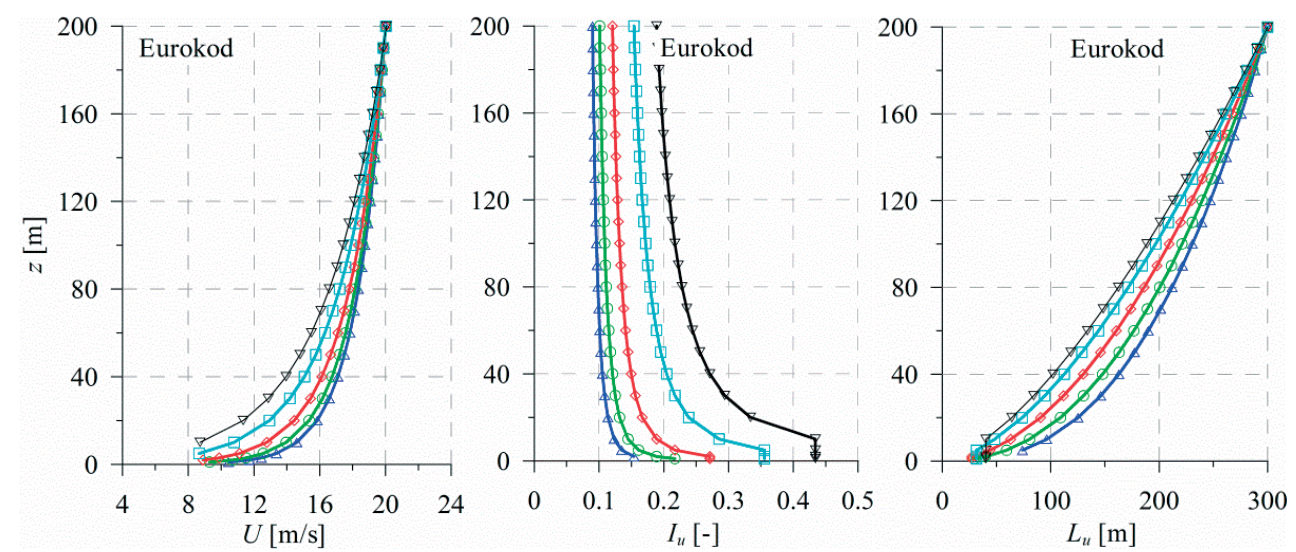

Fig. 3. Wind characteristics according to Eurocode (2008): a) mean wind speed profiles, log-law formula (on the right - flat open terrain, on the left - big city center, b) turbulence intensity profiles (on the right big city center, on the left - flat open terrain), c) turbulence length scale profiles (on the right - flat open terrain, on the left - big city center)

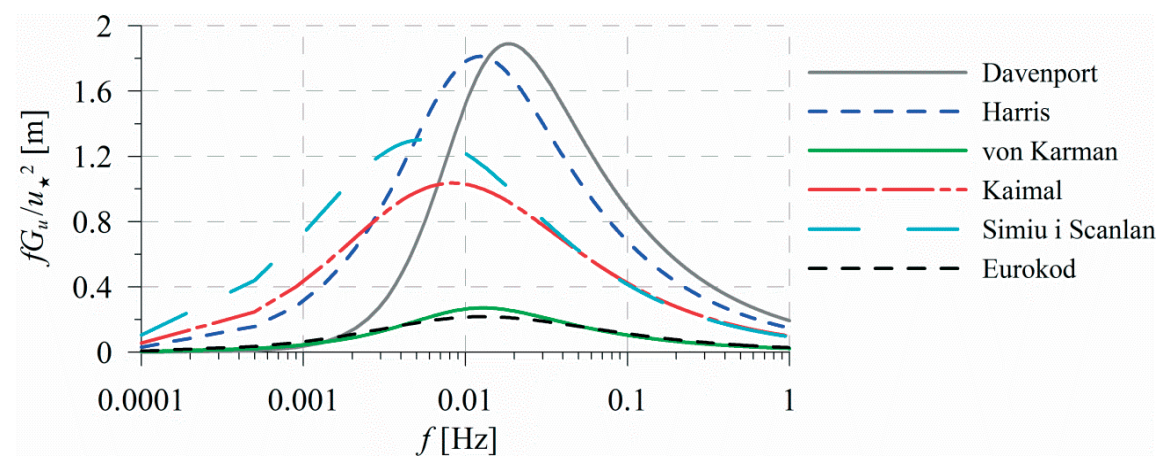

Fig. 4. Power spectral density (PSD) functions of component $u$ of wind speed according to various formulas

\subsection{Flow around bodies of different shapes}

Additionally to the wind characteristics, the character of flow in the close proximity of the objects of different shapes must be considered. In order to explain the flow phenomena that occurs in the vicinity of the body, let's consider the flow around a flat wall (Fig. 5). If the air flows around a flat, smooth surface, then in the effect of the viscous forces the movement slows down in its immediate vicinity. The area in which this phenomenon occurs is called the boundary layer. Within it, the speed varies from 0 at the surface, to the value in the undisturbed flow. The thickness of the boundary layer, i.e. the distance from the body surface to the height of undisturbed flow, ranges from a few millimeters to tens of centimeters (or to several hundred meters in $\mathrm{ABL}$ ). The thickness of the boundary layer increases with the distance from the first contact area of the air and the obstacle in the flow 
direction. The thickness of the boundary layer $\delta$ depends on the size of the body, its surface roughness, air viscosity, flow velocity and the nature of the flow itself, which can be laminar or turbulent.

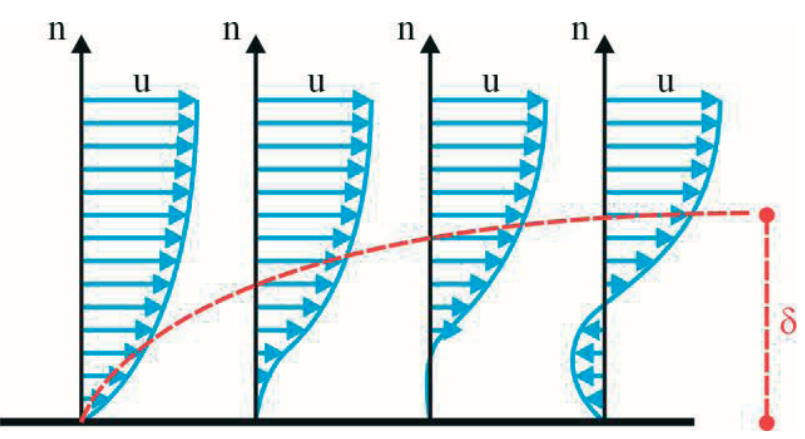

Fig. 5. Formation of boundary layer

Forces working in the boundary layer are: the inertial force resulting from the mass of the flow and the viscosity force that slows down the flow what causes the formation of a force tangential to the surface, opposite to the flow direction. We may also distinguish forces derived from the pressure, slowing or accelerating the flow depending on the pressure increase or decrease in the flow direction. The resultant effect of these forces may cause a slowdown in the flow, and consequently the possibility of the return movement (reversed flow), known as the boundary layer separation (detachment). The point on the surface to which the flow is returned is the point of separation (detachment) of the boundary layer. Sometimes also the term 'separation bubble' is used since the detachment occurs at a some length of the body. Beyond the point of separation, the reversed flow in a form of a vortex appears. The location of the area at the body surface, where the separation occurs, depends mainly on the shape and surface roughness of the body, velocity and the nature of the flow, which can be laminar or turbulent. Vortices formed in the flow can cause large suction on the surface of the object, of the largest value close to the point of detachment. The shape of the body is crucial for the flow features in its proximity.

If the object has a streamlined cross-section (e.g. airfoils), the air flow adapts to its shape. This kind of sections are used in aviation, or in wind energy engineering as a rotor blades.

The flow around bluff-bodies with sharp edges of a compact cross-sections and crosssections elongated in a direction perpendicular to flow depends on Reynolds number $-R e$. This dimensionless value represents the ratio of the inertia forces to the viscosity forces. In the field of civil engineering, high values of $R e$ will be taken into account, like $R e>10^{5}$. In the case of bluff-bodies with sharp edges, at $R e>1000$, the turbulent wake region (limited by smaller vortices) is formed. Shear layers separate the streamline flow area (no vortices) from the highly turbulent vortex area called aerodynamic wake (Fig. 6a).

In the case of bluff-bodies with sharp edges elongated in flow direction, boundary layer separates on the windward edges, then at side walls reattaches to the surface (so-called reattachment of the boundary layer), and next at leeward edges separates again to form a narrower wake region. The flow depends not only on the windward surface, but also on the dimensions of the object along the flow direction (Fig. 6b).

The flow around bluff-bodies of oval sections strongly depends on $R e$. For different ranges of $R e$, vortex shedding has different character from symmetrical shedding of two 
vortices, periodical shedding to quasi-periodical vortex shedding. For example, when $R e$ rises above $3.5 \cdot 10^{6}$ (super-critical range of $R e$ ) flow is completely turbulent, while vortex shedding exhibits a quasi-regularity (Fig. 6c).

a)

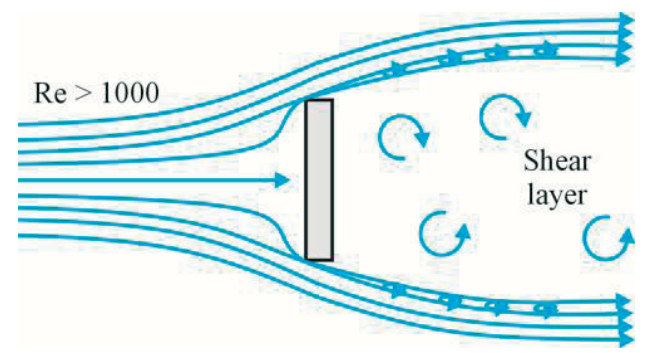

b)

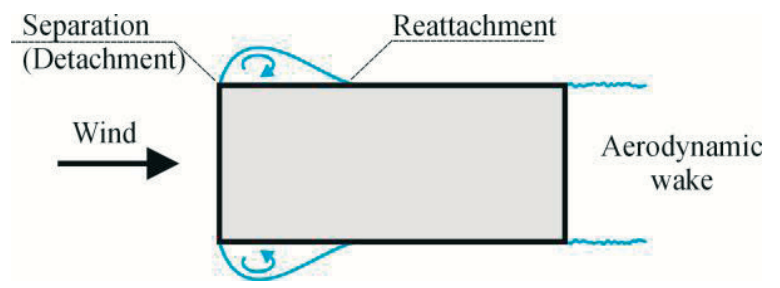

c)

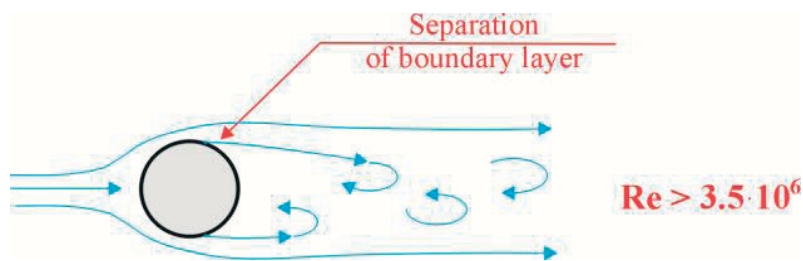

Fig. 6. Flow over different simple cross-sections in dependence on Re, a) sharp edged compact or elongated in across-wind direction, $\mathrm{b}$ ) sharp edged elongated along-wind direction, c) oval

The Navier-Stokes equations describe movement of the fluid (in our case - wind) with a use of the principle of mass and momentum conservation. The change of momentum of the fluid element depends on the external pressure and internal viscous forces in the fluid, and it can be represented by three components $u, v, w$ in the following form:

$$
\left\{\begin{array}{l}
\frac{d u}{d t}=F_{x}-\frac{1}{\rho} \frac{\partial p}{\partial x}+v\left(\frac{\partial^{2} u}{\partial x^{2}}+\frac{\partial^{2} u}{\partial y^{2}}+\frac{\partial^{2} u}{\partial z^{2}}\right)+\frac{v}{3} \frac{\partial}{\partial x}\left(\frac{\partial u}{\partial x}+\frac{\partial v}{\partial y}+\frac{\partial w}{\partial z}\right) \\
\frac{d v}{d t}=F_{y}-\frac{1}{\rho} \frac{\partial p}{\partial y}+v\left(\frac{\partial^{2} v}{\partial x^{2}}+\frac{\partial^{2} v}{\partial y^{2}}+\frac{\partial^{2} v}{\partial z^{2}}\right)+\frac{v}{3} \frac{\partial}{\partial y}\left(\frac{\partial u}{\partial x}+\frac{\partial v}{\partial y}+\frac{\partial w}{\partial z}\right) \\
\frac{d w}{d t}=F_{z}-\frac{1}{\rho} \frac{\partial p}{\partial z}+v\left(\frac{\partial^{2} w}{\partial x^{2}}+\frac{\partial^{2} w}{\partial y^{2}}+\frac{\partial^{2} w}{\partial z^{2}}\right)+\frac{v}{3} \frac{\partial}{\partial z}\left(\frac{\partial u}{\partial x}+\frac{\partial v}{\partial y}+\frac{\partial w}{\partial z}\right)
\end{array}\right.
$$

Using notations of pressure gradient (grad), divergence (div), Lagrange operator $\left(\nabla^{2}\right)$ and a material derivative $D / D t$, Navier-Stokes equations take the following form:

$$
\frac{\mathrm{D} \mathbf{u}}{\mathrm{D} t}=\mathbf{f}-\frac{1}{\rho} \operatorname{grad} p+v \nabla^{2} \mathbf{u}+\frac{v}{3} \operatorname{grad} \operatorname{div} \mathbf{u}
$$


Taking into account several assumptions, that:

1 The fluid is incompressible (the density is constant or its changes are negligible);

2 Fluid is inviscid, so its viscosity is omitted;

3 Flow is stationary, i.e. the derivatives of the velocity components with respect to time are equal to 0 ;

4 The external forces are ignored;

the Bernoulli equation for the stationary, inviscid and incompressible flow will be obtained:

$$
\frac{d \mathbf{u}}{d t}=-\frac{1}{\rho} \operatorname{grad} p
$$

After integration:

$$
p+\frac{1}{2} \rho u^{2}=\text { const }
$$

where: $u$ - fluid (wind) speed, $0.5 \rho u^{2}$ - dynamic pressure, $p$ - static pressure.

On the basis of the Bernoulli equation, the pressure (positive pressure) or suction (negative pressure) - the aerodynamic loads acting on the body placed in the air flow which is perpendicular to its surface, can be defined. The pressure on the outer walls of the objects is mainly determined experimentally. It is most convenient to use dimensionless values of pressure coefficients, which are independent on the wind velocity. In practice, the dimensionless coefficient is determined according to the relationship:

$$
C_{p}=\frac{\Delta p}{q_{\infty}}=\frac{p_{i}-p_{\infty}}{q_{\infty}}
$$

where: $p_{i}$ - surface pressure at point ' $i$ ', $p_{\infty}$ and $q_{\infty}$ - static pressure and wind speed pressure in undisturbed flow in the front of the object, $q_{\infty}=0.5 \rho u_{\infty}^{2}$. The pressure coefficients are difficult to define for the real structure surfaces (in full-scale experiments), due to the obvious reason - costs. Most of the studies are done in the model scale, usually in wind tunnels.

\subsection{Aeroelastic phenomena}

Any engineering structure can vibrate due to the action of:

- Inertia forces;

- Elasticity forces;

- Aerodynamic forces.

Dynamic phenomena connected with wind action are:

1. Forced vibrations - occur when the time varying external force (independent from the vibration of the structure) is applied. The example of such behaviour is the dynamic response of the structure.

2. Self-excited vibrations - the force disappears when the vibrations disappear. The vibrations are controlled by the vibration system itself - the feedback appears. Examples of such vibrations are flutter, vortex excitation, galloping.

The forced, damped vibrations of the given mass are described by the general motion equation:

$$
m \ddot{y}+c \dot{y}+k y=P_{0} \sin \left(\omega_{w} t\right)
$$


Dynamic features of the structure must be taken into account because dynamic wind action can cause resonance or at least vibrations of unaccepted level. Taking into account dynamic action of the wind and dynamic response of any structure which can vibrate in the wind field the following various wind actions can appear:

1 . Dynamic action of gusts.

The wind gusts can cause along-wind vibrations of the structure. Fig. 7 illustrates structure's response to wind gusts. The approach was originally developed by Alan Davenport (e.g. 1960, 1965) and currently is used in several wind codes.

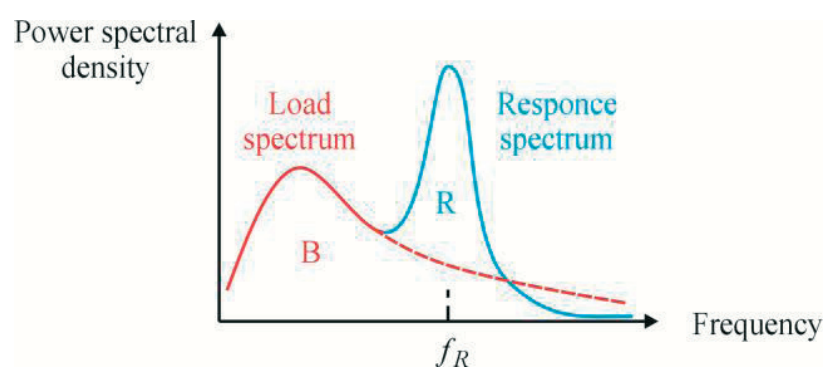

Fig. 7. Resonant (R) and background (B) parts of structure's response, according to Davenport's approach

\section{Vortex excitation.}

Von Kármán proved in 1912 that, the perfect periodical vortex street appears in case of circular cylinders in subcritical range of Reynolds number. When the frequency $f_{v}$ of vortex shedding is equal or near to the $i$-th natural frequency of the structure vibrations $f_{i}$ the possibility of resonance may occur. The phenomenon is called lock-in and means synchronization of frequencies of vortex shedding and structure vibrations. Classical vortex street and changes of the frequency and the amplitude of vibrations with the wind speed, explaining the lock-in phenomenon are shown in Fig. 8.

a)

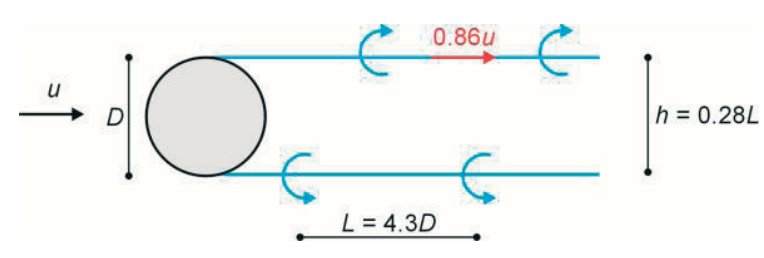

b)

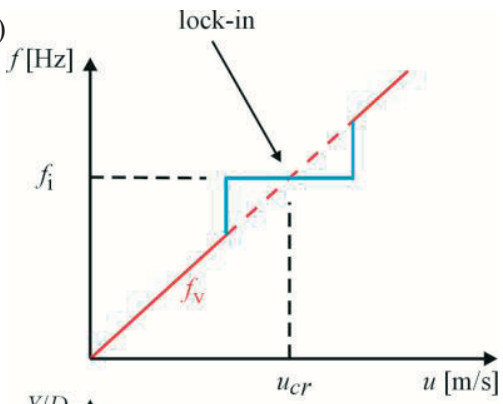

$Y / D$

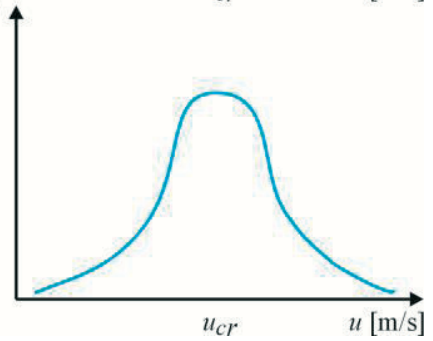

Fig. 8. a) Von Kármán vortex street, b) lock-in; frequency $(f)$ dependence on wind speed $(u)$; an increase of amplitude of lateral vibrations, $Y$ - lateral displacement, $D$ - diameter, $u_{c r}-$ critical wind speed 


\section{Galloping.}

A precondition for the galloping is an initial movement of the structure of small stiffness, caused e.g. by detachment of vortices, or by gusts. Most frequently, this phenomenon occurs on overhead power lines, guys of masts, cables of cable-stayed bridges. It is more likely that the galloping will occur if there is ice on a structure, or because of rain, which changes the aerodynamic properties of the cross-section. A scheme of the forces acting on the system during galloping is shown in Fig. 9a.

\section{Flutter.}

The phenomenon of flutter is generated due to the feedback between vibrations in the direction of different degrees of freedom. In the classic flutter problem which appears for aircraft wings or bridges, the feedback occurs between vertical and torsional vibrations. Such system with two degrees of freedom is shown in Fig. 9b.

Summing up, to assume realistic wind action on engineering structures, all above mentioned aspects (and many more) should be considered.

a)

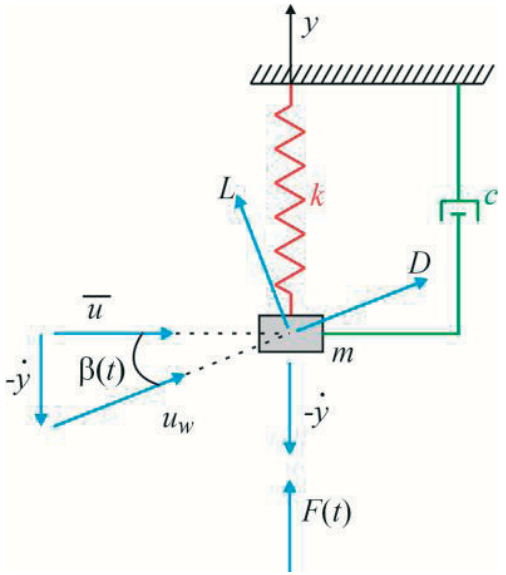

b)

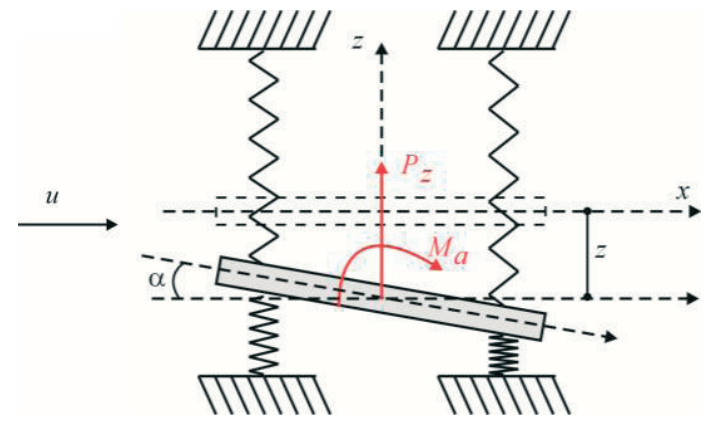

Fig. 9. a) Scheme of galloping, b) scheme of flutter of the system with two degrees of freedom

\section{Experimental methods}

When the wind action is analysed, the level of uncertainty is high. To maximize the accuracy, several parameters of wind load must be determined with care. There are three ways which allow to determine features describing wind actions. These are:

1. In-situ (full-scale, real scale) measurements.

2. Model scale measurements.

3. Numerical simulations.

\subsection{Full-scale tests}

Full-scale tests are obviously the most powerful tool in estimation of wind actions. Test could be performed on already erected objects, and thus could provide a database for designers of future structures. This leads to the basic limitation of full-scale tests which results are sometimes impossible to implement in new design or already erected structures. The second limitation is connected to the difficulty of proper instrumentation of the structure. The third, and probably the most important limitation, is a huge cost of measurement installation. Currently, there are limited data gathered from the full-scale experiments. 
The majority of results were derived from long-lasting monitoring of bridges, high-rise buildings and roofs of large spans, and also from meteorological measurements of wind field over different terrains. These tests supply data about wind flow around objects of different shapes, wind pressure on outer surfaces of objects or response of the structure to wind action which could be described by vibration accelerations.

To give the better view on various wind engineering full-scale tests, performed during recent years, some examples are enclosed below. The wind features were measured by Roth (2000) who analysed data about wind turbulence in urban areas. Li et al. (2010) described wind characteristics for urban terrain in Beijing, whereas He et al. (2013) gave description of the wind field in Hong Kong. Wind characteristics for conditions of open terrain were estimated by Shiau and Chen (2002) and Tieleman (2008). With the development of measurement techniques, wind engineering also engage more and more modern and advanced methods. Tamura et al. $(2001,2007)$ used Doppler sodars to measure wind characteristics over terrain of different roughness. Dominguez et al. (2013), Gonzalo et al. (2014) developed the measurement system based on particle tracking in the air.

Data from full-scale tests of buildings are rather limited. Dalgliesh (1975), Dalgliesh et al. (1983) was one of the pioneers in measurements of high-rise buildings. He made test of the 57-storey building in Toronto, measuring surface wind pressure and vibration response of the building.

There are objects which were measured in details in the full-scale as well as in the model-scale in wind tunnels through the years. Moreover, data obtained for these buildings are the validation base for several numerical methods. These are: SILSOE Building erected 1986/1987, of dimensions: $D=24 \mathrm{~m}, B=12.9 \mathrm{~m}, H=5.3 \mathrm{~m}$ (e.g. Richardson et al., 1997) and SILSOE Cube of dimensions: $D=B=H=6 \mathrm{~m}$ (e.g. Richards and Hoxey, 2008, 2012); CAARC - Commonwealth Advisory Aeronautical Research Council of dimensions: $D=45.72 \mathrm{~m}, B=30.48 \mathrm{~m}, H=182.88 \mathrm{~m}$ (e.g. Melbourne, 1980, Goliger and Milford, 1988, Huang et al., 2007); TTB - Texas Tech Building of dimensions: $D=13.7 \mathrm{~m}$, $B=9.1 \mathrm{~m}, H=4 \mathrm{~m}$. (e.g. Cochran and Cermak, 1992, Endo et al., 2006).

Recent years brought more data from long-term monitoring of the wind action and the response of large structures. The results concern wind field features around structures, surface wind pressures, displacements, velocities or accelerations of objects. Many tests are carried out during extreme winds like typhoons, cyclones, tornadoes, etc. For several buildings (among others: Di Wang Tower, China, $H=325 \mathrm{~m}$; Central Plaza Tower, Hong Kong, $H=374$ m; Guangzhou International Finance Centre, China, $H=432$ m; Jin Mao Buiding, China, $H=420,5 \mathrm{~m}$; Canton Tower, China, $H=610 \mathrm{~m}$; three buildings in Chicago) the results of extreme wind action were presented (e.g. Li et al., 2005, 2008, Li and Wu 2007, Fu et al., 2012, Guo et al., 2012, Bashor et al., 2012).

\subsection{Model-scale tests}

From the point of view of costs and accuracy, the reasonable alternative to full-scale tests is model-scale testing. The large advantage of such tests is that they are usually carried out when the engineering structure is still in the design stage. Such experiments are performed in water channels or mainly in wind tunnels. First, the scale model of the real structure is created and next it is placed in the special tunnel where artificial wind flow is created with the use of fans.

If the tests in the tunnel are intended to refer to a particular real object, it is necessary to perform appropriate model scaling and flow scaling. Unfortunately, a scaling process raises a number of problems. If one has to determine the external wind pressure on the 
object, then it is sufficient to scale the object's dimensions and mount the model rigidly in the tunnel. When data about structural response of the object are needed (e.g. structure vibrations induced by the wind load), the simple scaling of geometry is insufficient and appropriate scaling of stiffness and weight distribution along the height/span is necessary. The second scaling problem, often even more difficult to overcome, is the wind structure scaling, so that the boundary layer generated in the tunnel corresponds to the atmospheric boundary layer occurring in the reality. Appropriate (in relation to reality) model and flow scaling, is based on similarity analysis, which gives similarity criteria of objects and flows between model and real scale. Reliable experiments can be conducted, only when similarity criteria are fulfilled.

Through the years, the most common techniques used in wind tunnels were:

- Hot-wire anemometers (thermo-anemometers) measurements. They are used to measure the instantaneous velocity of flow in one or two (sometimes three) directions. Measurements with the use of hot-wire anemometers were made by e.g. Bartoli et al. (2006), Kim and Han (2011), Pozzuoli et al. (2013), Błazik-Borowa et al. (2011), Bęc et al. (2011).

- Pressure measurements. Pressure taps are mounted on the surface of the object and then connected by thin tubes to the pressure transducer, which is placed outside the model, or even outside the tunnel. The transducer measures pressure difference between the pressure tap placed on the building surface and the reference pressure tap. Recently, pressure measurements were performed by e.g. Aly (2013), Rizzo (2012), Elsharawy et al. (2015), Yi and Li (2015), Bell et al. (2016), Taylor et al. (2014), Cluni et al. (2011), Pozzuoli et al. (2013), Hu et al. (2015), Kim et al. (2015), Šarkić et al. (2015), Lipecki (2015), Lipecki and Jamińska (2012).

- Force measurements on force balance. The force balance allows for direct measurement of components of the global aerodynamic force and moment. The force balance is equipped with the set of strain gauges in the specific arrangement. On the basis of the stresses in the force balance elements, calculated from the strain gauges measurements, global forces and moments acting on the model are derived. Such technique was used by e.g. Aly (2013), Yi and Li (2015), Cluni et al. (2011), Šarkić et al. (2015), Letchford et al. (2016).

- Measurements of displacements, velocities and accelerations. There are various types of sensors that can measure displacements, velocities or accelerations (in one, two or three directions). Such devices are useful, for example in vibrations frequency measurements, and are used mainly for aeroelastic models. Accelerations were measured by e.g. Bęc et al. (2013).

- Flow visualization. Visualization is used mainly to study the flow around objects. There are different methods of flow visualization, they could be very simple, like: threads, powdered pigments, smoke, or more advanced, like: smoke or airborne particles which are accompanied by photographs of laser-lighted planes. Flow visualization was used by e.g. in Ozmen et al. (2016), Bell et al. (2016), Hu et al. (2015), Afshin et al. (2016).

As more recent and developed techniques used in wind tunnels, the following can be listed:

- Laser Doppler Velocimetry - LDV (Laser Doppler Anemometry - LDA). This technique uses laser to measure the velocity in the flow. The LDA uses the Doppler effect - shift in the light frequency emitted by the source (in this case, the laser) and registered by the observer. It requires markers in the form of particles in the flow. 
LDA was recently used e.g., by: Kim and Han (2011), Carpentieri and Robins (2015).

- Particle Image Velocimetry (PIV). It is another technique used to measure the flow velocity. Similarly, as in the LDA, it requires particles floating in the flow. In the PIV, two pictures one after another are taken and the distance over which particles migrated in this short period of time is calculated. Thanks to its broad potential, PIV is more often used recently, e.g., by: Taylor et al. (2014), Oguma et al. (2013), Jin et al. (2015).

The wide review of existing wind tunnel techniques used mainly for pedestrian wind comfort was recently made by Blocken et al. (2016).

Last years brought new opportunities to wind action measurements. The Wall of Wind (WOW), Florida, USA, is the battery of large fans which allows to perform simulations in the real scale or in the intermediate scale between full and model (for instance 1:10). It is mainly used for tests connected to hurricanes or wind-driven rain impact on structures (Mooneghi et al., 2014, Blessing et al., 2009, Beheru et al., 2014, Aly et al., 2012, Habte et al., 2015). In 2011, next to the existing tunnels in the University of Western Ontario, a special wind tunnel for tornadoes, and downbursts accompanying hurricanes, was created The Wind Engineering, Energy and Environment Research Institute, so-called WindEEE (Refan et al., 2014, 2016).

\subsection{Numerical simulation}

Computational Wind Engineering (CWE) and Computational Fluid Dynamics (CFD) consist of various types of flow numerical simulations, objects-flow interactions, etc. When talking about CWE one can consider, for example, the simulation of the wind field as the stochastic process. CFD focuses on simulations of turbulent flows around different structures. Recently, the wide summary of CFD past and current achievements, as well as future challenges in wind engineering applications, was described by Blocken (2014).

There are numerous methods which allow to perform simulations of turbulent flows (corresponding to atmospheric flows). CFD methods, adopting different flow models, are: DNS (Direct Numerical Simulation), RANS (Reynolds-Averaged Navier-Stokes), LES (Large Eddy Simulation), DVM (Discrete Vortex Method). Results obtained in wind engineering and building aerodynamics simulations are still not clear and must be based on extensive theoretical knowledge. Therefore, CFD simulations are usually accompanied by model or in situ tests, and the results apply only to the analysed case. Numerical simulations still need to be validated experimentally. Computer simulations are relatively not expensive, but due to the validation necessity, costs can increase dramatically. The large advantage of CFD is that after validation of one case, other cases, e.g. associated with the changes of the angle of wind attack, could be also computed. Graphical summary of methods with respect to the accuracy, the speed of operation and the associated costs, is represented by the diagram shown in Fig. 10.

While conducting CFD analyses, a special attention should be paid to several recommendations, use of which will increase the correctness of obtained results. The most important of them are:

1. For all methods based on grid discretization, the final calculations should be preceded by a grid sensitivity analysis. The correct solution should be grid-independent.

2 . The results of simulations should be carefully checked on the basis of model or insitu experiments, or in the absence of such results, on the basis of the literature. Up to the present moment, considerable database of flows around single buildings, or systems of 
buildings was created. The process of comparing the results of simulations and tests is called validation. Verification, however, refers e.g. to checking if the correct mathematical model was used in the phenomenon description, or to checking the correctness of the program code. (Gousseau et al., 2013).

3. Numerical simulations should be carried out in accordance with the guidelines described thoroughly in the literature. The guidelines are based on calculations accurately validated with experimental results. They relate mainly to the size of the computational domain and the distance between the model and domain walls, the number of cells used along model edges, etc. The most detailed guidelines for CFD study were presented, among other papers, by Franke et al., 2007, 2011, Yoshie et al., 2007, Tominaga et al., 2008, Tamura et al., 2008.

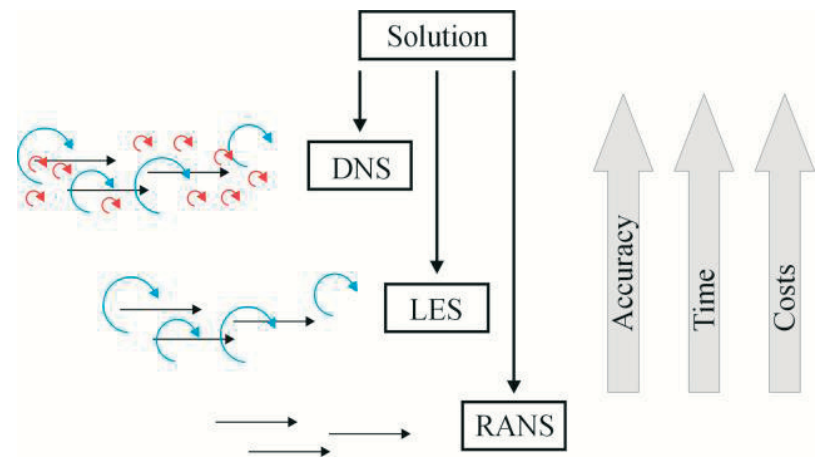

Fig. 10. Relations between methods of solving N-S and continuity equations

The topics most frequently considered in CFD deal with: atmospheric boundary layer simulations, bluff body aerodynamics, pedestrian-level wind conditions, air pollutant dispersion, flow over complex terrain, ventilation of buildings, wind-driven rain, snow distribution, wind loads on buildings and structures, assessment of wind farms localization, aerodynamics of wind turbines, road vehicle aerodynamics, trains aerodynamics, windborne flying debris, sport aerodynamics, etc.

\section{Current and future issues in wind engineering}

The review of recent major topics, undertaken by wind engineering and structure aerodynamics, was made on the basis of the papers published recently, and on the basis of presentations showed during the most important "wind" conferences. The main journal which deals with the subject is Journal of Wind Engineering and Industrial Aerodynamics. The division of main topics of all papers published in JWEIA since 2013 till April, 2016 is compiled in Table 1. Of course, this division is subjective, because in some papers several issues were considered. For example, the development of CFD techniques is presented with the case study related to the cable-stayed bridge or wind turbine, wind loads on roofs are calculated for atmospheric boundary layer as well as for tornado or hurricane, wind structure is described in details on the occasion of wind loads estimation for different structures, etc. Each paper was classified to one topic only, what gave the overall view on major topics. The great majority of papers included: wind tunnel tests, full-scale tests or CFD studies performed for the given structure or the group of structures. In every case, numerical simulations were validated with respect to wind tunnel or full-scale tests. 
There are six major conferences related to wind engineering field of study. These are: International Conference on Wind Engineering (ICWE14, every 4 years, last $-14^{\text {th }}$ in Brazil, 2015), European \& African Conference on Wind Engineering (EACWE6, every 4 years, last $-6^{\text {th }}$ in UK, 2013), Asia-Pacific Conferences on Wind Engineering (APCWE8, every 4 years, last $-8^{\text {th }}$ in India, 2013), American Conference on Wind Engineering (ACWE12, every 4 years, last $-12^{\text {th }}$ in USA, 2013), International Symposium on Computational Wind Engineering (CWE6, every 4 years, last $-6^{\text {th }}$ in Germany, 2014), International Colloquium on Bluff Body Aerodynamics and Applications (BBAA7, every 4 years, last $-7^{\text {th }}$ in China, 2012). The division of topics mentioned during last conferences, similar to the division presented above, is collected in Table 2. Since many more issues were addressed, the additional topics were added.

Table 1. Review of topics published in JWEIA in period 2013 - April, 2016

\begin{tabular}{|c|c|c|c|c|}
\hline Topic & 2013 & 2014 & 2015 & 2016 \\
\hline Flow over complex terrain, terrain local topography & 2 & 2 & 6 & 1 \\
\hline Wind field description, wind structure, modelling of wind in CFD & 17 & 12 & 11 & 7 \\
\hline Extreme winds, typhoons, cyclones, hurricanes, downbursts & 8 & 9 & 13 & 4 \\
\hline Tornadoes & 3 & 2 & 6 & 2 \\
\hline Circular, elliptic, oval cross-sections (cylinders), also cables & 7 & 7 & 5 & 1 \\
\hline Bridges, pylons, decks, flutter & 11 & 17 & 12 & 1 \\
\hline Square, rectangular cross-sections, prisms, low-rise buildings & 6 & 13 & 13 & 3 \\
\hline Roofs & 6 & 6 & 9 & 3 \\
\hline High-rise buildings & 6 & 4 & 8 & 1 \\
\hline Interference, shielding effect, arrays of buildings & 3 & 1 & 6 & 1 \\
\hline Towers, masts, chimneys, lattice structures & - & 3 & 3 & 1 \\
\hline $\begin{array}{l}\text { Uncommon structures (e.g. domes, tanks, monument structures, cooling } \\
\text { towers, road signs, windbreakers, membrane structures, scaffoldings, air- } \\
\text { cushion vehicles, etc.) }\end{array}$ & 4 & 8 & 7 & - \\
\hline Transmission lines & - & 1 & - & - \\
\hline Subway, road, rail tunnels & 1 & - & 3 & - \\
\hline Porous media & 2 & 3 & - & - \\
\hline Dampers and damping & 3 & 1 & 1 & - \\
\hline $\begin{array}{l}\text { Vibration comfort in buildings, thermal comfort in buildings, human body } \\
\text { reaction to vibrations }\end{array}$ & 2 & 3 & - & - \\
\hline Railway aerodynamics, high-speed trains, trains & 5 & 10 & 12 & 2 \\
\hline Road vehicles aerodynamics, trucks & 5 & 6 & 11 & 2 \\
\hline Wind energy, wind farms, wind turbines, airfoils & 32 & 25 & 40 & 9 \\
\hline Solar collectors, panels, farms & 8 & 4 & 3 & - \\
\hline $\begin{array}{l}\text { Pedestrian level wind comfort, smoke dispersion, pollutant dispersion, } \\
\text { ventilation in urban areas }\end{array}$ & 6 & 1 & 4 & 1 \\
\hline Rain load, wind-driven rain & 3 & 4 & 5 & - \\
\hline \begin{tabular}{|l|} 
Snow-wind load \\
\end{tabular} & - & - & 1 & - \\
\hline Ice load, accretion & 1 & - & 1 & - \\
\hline Forests, trees, vegetation & 2 & 1 & 1 & - \\
\hline Windborne flying debris & - & 1 & 2 & - \\
\hline Standards and codes & - & 3 & - & - \\
\hline Sport aerodynamics & - & 2 & 2 & - \\
\hline Sail aerodynamics & - & - & 1 & - \\
\hline $\begin{array}{l}\text { Other (e.g. CFD theory, CFD development, CFD grid verification, wind } \\
\text { tunnel description, wind engineering review, etc.) }\end{array}$ & 3 & 5 & 8 & - \\
\hline
\end{tabular}


Table 2. Review of topics presented during last major conferences in wind engineering

\begin{tabular}{|c|c|c|c|c|c|c|}
\hline Topic & a) ${ }^{*}$ & b) ${ }^{*}$ & c) $)^{*}$ & d) $)^{*}$ & e) $)^{*}$ & f) $)^{*}$ \\
\hline Flow over complex terrain, terrain local topography & 3 & 2 & 1 & 1 & 6 & 5 \\
\hline $\begin{array}{l}\text { Wind field description, wind structure, modelling of wind in } \\
\text { CFD, wind characteristics measurements }\end{array}$ & 9 & 13 & 10 & 14 & 31 & 39 \\
\hline $\begin{array}{l}\text { Extreme winds, typhoons, cyclones, hurricanes, downbursts, } \\
\text { wind storms, wind hazard assessment, wind vulnerability and } \\
\text { risks }\end{array}$ & 8 & 4 & 36 & 17 & 3 & 52 \\
\hline Tornadoes & 2 & - & 12 & 2 & 2 & 12 \\
\hline Circular, elliptic, oval cross-sections (cylinders), also cables & 9 & 5 & 2 & 3 & 4 & 13 \\
\hline Bridges, pylons, decks, flutter & 49 & 24 & 26 & 17 & 17 & 46 \\
\hline $\begin{array}{l}\text { Square, rectangular cross-sections, prisms, low-rise, medium- } \\
\text { rise buildings }\end{array}$ & 32 & 11 & 7 & 11 & 11 & 40 \\
\hline Roofs, large-span roofs, stadium roofs & 10 & 4 & 13 & 10 & 3 & 24 \\
\hline High-rise buildings & 11 & 9 & 15 & 14 & 8 & 37 \\
\hline Interference, shielding effect, arrays of buildings & 8 & 6 & 3 & 10 & - & 12 \\
\hline $\begin{array}{l}\text { Towers, masts, chimneys, lattice structures, cranes, slender } \\
\text { structures }\end{array}$ & 2 & 2 & - & 8 & 1 & 14 \\
\hline $\begin{array}{l}\text { Uncommon structures (e.g. domes, tanks, monument structures, } \\
\text { cooling towers, road signs, membrane structures, scaffoldings, } \\
\text { air-cushion vehicles, helicopters, inflatable structures, air- } \\
\text { cooler condensers windshields, traffic light structures, cyclone } \\
\text { shelters, spiked cross-sections, lighting poles, silo, pyramids, } \\
\text { etc.) }\end{array}$ & 13 & 7 & 8 & 5 & 7 & 11 \\
\hline Transmission lines & 1 & 1 & 1 & 2 & 4 & 9 \\
\hline Subway, road, rail tunnels & - & 1 & - & - & 2 & - \\
\hline Porous media, permeable elements & 3 & - & - & 1 & - & 3 \\
\hline Dampers and damping & 1 & 6 & 2 & 4 & 2 & 7 \\
\hline $\begin{array}{l}\text { Vibration comfort in buildings, thermal comfort in buildings, } \\
\text { human body reaction to vibrations, ventilation in buildings, } \\
\text { internal pressure in buildings }\end{array}$ & - & 4 & 1 & 4 & 9 & 4 \\
\hline Railway aerodynamics, high-speed trains, trains & 5 & 6 & 1 & 1 & 4 & 2 \\
\hline Road vehicles aerodynamics, trucks & 5 & 2 & - & 2 & 2 & 5 \\
\hline Wind energy, wind farms, wind turbines, airfoils & 1 & 10 & 21 & 23 & 17 & 33 \\
\hline $\begin{array}{l}\text { Solar collectors, panels, farms, panel arrays, photovoltaic } \\
\text { systems }\end{array}$ & 1 & 4 & 6 & 4 & 2 & 11 \\
\hline $\begin{array}{l}\text { Pedestrian level wind comfort, smoke dispersion, pollutant } \\
\text { dispersion, ventilation in urban areas, traffic pollution, thermal } \\
\text { environment, street canyons }\end{array}$ & 12 & 10 & 3 & 5 & 34 & 21 \\
\hline Rain load, wind-driven rain & 3 & - & 1 & - & 2 & 9 \\
\hline Snow-wind load, snow drifts, snow particles & - & 2 & - & 2 & 3 & 3 \\
\hline Ice load, accretion & 1 & 4 & 1 & 1 & - & 6 \\
\hline Forests, trees, vegetation & 4 & - & - & - & 4 & 2 \\
\hline Windborne flying debris & 1 & - & 5 & 2 & 1 & 1 \\
\hline Standards and codes & - & 6 & 11 & 1 & - & 5 \\
\hline Sport aerodynamics & 1 & 2 & - & - & - & - \\
\hline Sail aerodynamics & - & 2 & - & - & 2 & - \\
\hline $\begin{array}{l}\text { Other (e.g. CFD theory, CFD development, CFD grid } \\
\text { verification, wind tunnel description, wind engineering review, } \\
\text { measurement techniques, terminology etc.) }\end{array}$ & 5 & 10 & 12 & 13 & 27 & 30 \\
\hline \multicolumn{7}{|c|}{\begin{tabular}{|ll} 
* columns description: & $\begin{array}{l}\text { a) BBAA7, 2012, b) EACWE6, 2013, c) ACWE12, 2013, } \\
\text { d) APCWE8, 2013, e) CWE6, 2014, f) ICWE14, 2015 }\end{array}$ \\
\end{tabular}} \\
\hline
\end{tabular}


The largest number of published papers was devoted to wind energy. The field of wind energy is wide and it is connected with optimization of airfoils and wind turbines. Many of articles referred to CFD simulations and wind tunnel measurements of different types of wind turbines: with horizontal (HAWT) and vertical (VAWT) axis. Large wind farms consisting of clusters of wind turbines were also investigated. Some papers also considered the possible localization of wind farms with respect to energy harvest. More frequently FSI (fluid-structure interaction) and transient numerical simulations were used as the main tool of analyses.

The methods of wind field description are still being developed. Modern measurement techniques allow to perform more exact measurements of wind characteristics in atmospheric boundary layer (ABL). Both, the results of measurements in microscale (less than $2 \mathrm{~km}$ ), as well as in macroscale (synoptic scale, several hundreds of $\mathrm{km}$ ) are used in wind engineering. Description of the wind field as the non-Gaussian process is applied to downbursts and is currently being developed. Numerical methods of simulation of Gaussian and non-Gaussian type processes are being expanded. Another problem is connected to the correct implementation of ABL to wind tunnel measurements and to CFD simulations. Whereas, the first matter is rather well known (but still needs investigation), the second is currently under strong interest of researchers. The proper representation of $\mathrm{ABL}$, both in wind tunnels and in numerical domain, results in simulations with the conditions closer to the reality.

Bridges, as one of the most spectacular structures, and moreover - structures which every year are designed with larger spans, and for which wind action could be a dimensioning load, are under continuous attention of wind engineers. Different models of flatter and buffeting load are developed. Full-scale and wind tunnel results, as well as CFD calculations (sometimes all three experiments together) were presented for various cable-stayed bridges, suspension bridges, footbridges, etc. Optimization of a bridge deck was also investigated.

Many papers dealt with bluff body aerodynamics. Wind tunnel tests concerned flow around circular, square, rectangular 2D cross-sections as well as 3D prisms of different cross-sections. Several papers considered bridge cables of circular cross-section, galloping phenomena of slender elements, etc. The low-rise and medium-rise buildings, which shapes are predominantly rectangular or square, were also included in that topic. Various investigations such as measurements of wind field around buildings, pressures on the outer surfaces or wind impact on claddings were performed.

Large emphasis was also put on extreme winds, like: cyclones, typhoons, tropical storms and tornadoes. Modelling of such extreme wind events concerned mainly downbursts, which precede thunderstorms, and also tornadoes in relation to their impact to the engineering structures. Nowadays, it is possible to model tornadoes in model scale (see WindEEE) as well as in CFD. There were also presented some data from full-scale monitoring of engineering structures, mainly of high-rise buildings during extreme wind events. Another very important issues are: wind hazard assessment and wind vulnerability of structures. These topics are, in many regions of the world, crucial to local people and to strength of structures placed there.

Many papers and conference presentations concerned roofs of various shapes. For the basic rectangular shapes, pressure distribution was investigated, sometimes with respect to so-called conical vortices - vortices which cause large suction on the roof, close to its edge. Surface pressures and the influence of parapets or attics on the flow over the roof were also considered. Different shapes of rectangular roofs, for example stepped roofs, were checked in wind tunnels, full scale or in CFD. Practical problems like different kinds of linings, green roofs with gardens on the top of high-rise buildings, etc. were analysed. Large span roofs over halls or stadiums were measured and also calculated in CFD. 
Wind action is dominant in case of high-rise buildings and cannot be neglected. In their case, different combinations of load should be investigated (sometimes crosswind load connected with torsional load could be larger than along-wind load). Modern high-rise buildings are almost always of complicated shapes, based on basic rectangles or ovals. They may have corner modifications, be tilted, tapered, helical, have setbacks, openings or combine various features. It makes every of them a unique structure, vulnerable to the wind load, and that is why they must be modelled and examined in wind tunnel tests.

From the point of view of urban planning and people living in existing settlements, a very important issue is wind comfort at pedestrian level. It is connected to the wind speed which can accelerate significantly in flow contractions (such as those between buildings). The topic of pedestrian comfort is also connected to dispersion of snow during winters, or dispersion of smoke, gases and pollutants all over the year, or to the natural ventilation of the given area. The pollutant dispersion could be analysed in the scale of the building and its nearest surroundings (for example smoke from the chimney on the building roof) or in the scale of the district or even the whole city. Nowadays, CFD simulations play the major role in investigations of pedestrians wind comfort and pollutant dispersion.

Recently, mainly in journal papers, issues connected to road and rail aerodynamics arose. This topic concerns optimization of the aerodynamic shape of road and rail vehicles. Another topic relates to high-speed trains (introduced in many countries in last decade), their shape, but also their impact on the passengers and the vicinity. More frequently, some papers about coupling between vibrations of the structure (for example of the bridge), traffic and wind action were published. These problems can be investigated theoretically or with use of numerical methods, or experimentally. The possibility of the freight railway wagons to roll-over in strong winds was also the matter of interest in recent papers.

Another subject connected with cities and urban planning is an interference phenomenon. It could be interference between high-rise buildings in different configurations, but also between circular hangers of the bridge placed one by one. The influence of the highrise building on the roof of the medium-rise building placed nearby, was also the point of interest of some researchers. Sometimes, the effect of the windward structure on the leeward structure is called shielding effect.

In the civil engineering structures, the group of slender vertical objects containing: towers, chimneys, masts, lattice towers and cranes was distinguished. Different aspects of wind loads, and different aerodynamic phenomena which appear for these objects, were examined in full-scale, model scale or numerically.

Other engineering structures were grouped as uncommon structures. Papers in this group dealt with large structures like domes of various curves, tanks and siloes, cooling towers, pyramids, monument brick structures, membrane structures like umbrellas, inflatable structures, etc. Wind action was also analysed for smaller objects like road signs, traffic lights structures, lighting poles, scaffoldings, cyclone shelters, road windshields, aircooler condensers or for uncommon vehicles like helicopters or air-cushion vehicles. The analyses were sometimes performed in full-scale, but more frequently in model scale in wind tunnels or with use of CFD.

Four groups of other structures described a few times in papers and presentations were distinguished. They are tunnels, solar panels, porous structures and transmission lines. Different experiments with road or rail tunnels were carried out, they included fire propagation, car exhaust propagation, ventilation, etc. Solar panels are another green source of energy beside wind farms. Optimization of pitch angle of solar collectors, their localization on large span-roofs and spacing between collectors, or wind conditions in 
terrains under solar farms, etc., were the main subjects of interest in this topic. Porous structures are mostly windbreakers placed along roads. The flow through such objects is different than in case of solid ones, and so the wind load is also different. Recently, CFD simulations also addressed this problem. Yet another group of structures are transmission lines and their supporting structures. Dynamic wind action and galloping of lines were main issues of investigations in this topic.

Another part of wind engineering experiments describes flow over complex terrains. Mainly local changes in terrain topography such hills, edges, slopes and valleys were considered (usually investigated with use of CFD simulations). The main results obtained from such tests were wind speed multipliers.

Codification of wind loads is still under elaboration. Calculations carried out according to several standards often give significantly different results. Of course, it is mainly caused by local wind environment and different statistical tools used to describe wind characteristics. There are continuous works on improvements of the wind load description.

The impact of wind on forests, vegetations, single trees and orchards was also taken under consideration. This issue is important mainly for windy places around the world with an intensive agriculture. Respective representation of trees was usually examined in model tests or CFD simulation.

Damping (connected to structures and wind action) was another subject investigated by the researchers. Model tests give reasonable answer how dynamic properties of bridges, highrise buildings or other slender structures would change when dampers are assembled to the structure. In many places around the world, damping of the structure's response to wind action connected with seismic action is one of the most important problems faced by civil engineers.

Damping of structures is accompanied by another interesting question - how people in high-rise building will react on building vibrations? Full-scale tests of such comfort were performed in high-rise buildings or in special vibrating chambers (where real conditions are simulated). The response of the human body to vibrations was also examined. The internal wind comfort connected with thermal comfort and ventilation are another issues for building occupants.

Environmental actions combined with wind action were also often investigated. This could be wind driven-rain and its impact on buildings. Rivulet or rivulets can form on the surfaces of inclined cables of masts or cable-stayed bridges. They change significantly the aerodynamic properties of the cross-section of the cable and make them susceptible to galloping. Recently, also CFD studies considered this problem. Another environmental action is caused by wind and snow. Accumulation of snow in windy conditions and transport of accumulated snow caused by wind action in terrain or on roofs (so-called snowdrifts) were widely examined by full-scale tests, model tests and CFD simulations. Yet another issue was ice load and ice accretion. Ice storms are relatively rare, but ice accretion on lattice structures, transmission lines or cables can cause dangerous behaviour of the structures and even lead to collapse.

Windborne flying debris are another matter which was considered more frequently. Hurricanes, cyclones, tornadoes, and even strong (not extreme winds), can raise parts of elements or whole small elements from the ground and carry them. They can strike buildings and destroy their façades. This problem was studied in full-scale, and recently also in wind tunnels and with use of CFD.

The relatively new issue for wind engineers is sport aerodynamics. Various experiments on soccer balls, cyclists, ski jumpers or downhill runners were performed. More money is invested in sports, so the need of new investigations also appears. Sail aerodynamic was also considered. 
There are always many papers and conference articles about theoretical development of the given problem. Recently, mainly CFD development is theoretically described, and concerns governing equations, methods of solutions or grid improvements in simulations. Systematically, the reviews of achievements of wind engineering or presentations of the new facilities for wind study, or new measurement techniques appeared.

\section{Conclusions}

This paper gives a short description of the bases of wind engineering and aerodynamics of structures. Wind field characteristics, the flow around different bodies, governing equations and aeroelastic phenomena are also shortly explained. Three methods of investigations are described: full-scale tests, wind tunnel tests and CFD simulations. Finally, the review of the contemporary topics considered in the wind engineering is given. The number of published papers and given presentations during conferences is an indicator of the significance of the wind engineering topic.

It seems that CFD techniques are in constant development. The computer power rises, new modelling methods appear and there are more and more case studies well validated with model or full-scale tests. More advanced CFD techniques like LES, DES or unsteady RANS give better results (better validation) of many wind engineering problems. Also fullscale test are on rise because of new possibilities and more common monitoring of large structures. It seems that wind tunnel tests will remain on the same level as previously or their number will also rise. The major argument for this is that the measurement techniques in wind tunnel test are more diverse nowadays (e.g. PIV, LDA, etc.) and give more exact results. The necessity of CFD validation makes tunnel tests still a basic experimental tool in wind engineering. New wind facilities, like WOW or WindEEE, open the new perspectives for scientists. Moreover, the tendencies to build longer and higher, and to design structures of unexpected and futuristic shapes will definitely ensure the work to wind engineers.

The very up-to-date problem is the risk evaluation of extreme wind events and the assessment of hazards connected to it. For engineers, the main purpose is to design structures resistant to even extreme winds. Such issues, like windborne flying debris or the description of non-Gaussian processes, associated with extreme winds, must be considered.

The issue of green energy would develop more intensively in the next years, due to climate changes. In developed countries - there is a necessity to reduce various pollutions, in more poor countries - there is a need for cheaper energy. That is why different matters associated with wind and solar energy will be investigated even more frequently in the near future.

\section{References}

1. Afshin M., Sohankar A., Manshadi M.D., Esfeh M.K. An experimental study on the evaluation of natural ventilation performance of a two-sided wind-catcher for various wind angles. Renewable Energy 85 (2016) 1068-1078.

2. AIJ-RBL-1996. Recommendations for Loads on Buildings. Architecture Institute of Japan, 2004.

3. Aly A.M. Pressure integration technique for predicting wind-induced response in high-rise buildings. Alexandria Engineering Journal 52 (2013) 717-731.

4. Aly A.M., Bitsuamlak G.T., Chowdhury A.G. Full-scale aerodynamic testing of a loose concrete roof paver system. Engineering Structures 44 (2012) 260-270.

5. AS/NZS - Structural design actions - Part 2: Wind actions. Australian/New Zealand Standard. 
6. ASCE. Minimum design loads for buildings and other structures. Revision of ASCE 7-98, Reston, Virginia, USA, 2003.

7. Baheru T., Chowdhury A.G., Bitsuamlak G., Masters F.J., Tokay A. Simulation of wind-driven rain associated with tropical storms and hurricanes using the 12-fan Wall of Wind. Building and Environment 76 (2014) 18-29.

8. Bartoli G., Cluni F., Gusella V., Procino L. Dynamics of cable under wind action: Wind tunnel experimental analysis. Journal of Wind Engineering and Industrial Aerodynamics 94 (2006) 259-273.

9. Bashor R., Bobby S., Kijewski-Correa T., Kareem A. Full-scale performance evaluation of tall buildings under wind. Journal of Wind Engineering Industrial Aerodynamics 104-106 (2012) 88-97.

10. Bęc J., Lipecki T., Błazik-Borowa E. Pomiary drgań aeroelastycznych modeli masztów $z$ odciagami w tunelu aerodynamicznym. Budownictwo i Architektura 12(1) (2013) 211-218.

11. Bęc J., Lipecki T., Błazik-Borowa E. Research on wind structure in the wind tunnel of Wind Engineering Laboratory of Cracow University of Technology. Journal of Physics: Conference Series 318 (2011) 072003, doi: 10.1088/1742-6596/318/7/072003.

12. Bell J.R., Burton D., Thompson M.C., Herbst A.H., Sheridan J. Flow topology and unsteady features of the wake of a generic high-speed train. Journal of Fluids and Structures61 (2016) $168-183$.

13. Błazik-Borowa E., Bęc J., Nowicki T., Lipecki T., Szulej J. The measurements of parameters for 2-D flow around square and rectangular cylinders at the ground. Archives of Civil and Mechanical Engineering, XI(3) (2011) 533-551.

14. Blocken B. 50 years of Computational Wind Engineering: Past, present and future. Journal of Wind Engineering and Industrial Aerodynamics 129 (2014) 69-102.

15. Blocken B., Stathopoulos T., van Beeck J.P.A.J. Pedestrian-level wind conditions around buildings: Review of wind-tunnel and CFD techniques and their accuracy for wind comfort assessment. Building and Environment 100 (2016) 50-81.

16. Carpentieri M., Robin A.G. Influence of urban morphology on air flow over building arrays. Journal of Wind Engineering and Industrial Aerodynamics 145 (2015) 61-74.

17. Cermak J.E. Application of fluid mechanics to wind engineering. A Freeman Scholar Lecture. ASME Journal of Fluids Engineering 97(1) (1975) 9-38.

18. Cluni F., Gusella V., Spence S.M.J., Bartoli G. Wind action on regular and irregular tall buildings: Higher order moment statistical analysis by HFFB and SMPSS measurements. Journal of Wind Engineering and Industrial Aerodynamics 99 (2011) 682-690.

19. CNS - Load code for the design of building structures, China National Standard.

20. Cochran L.S., Cermak J.E. Full-and model-scale cladding pressures on the Texas Tech University experimental building. Journal of Wind Engineering and Industrial Aerodynamics 43(1-3) (1992) 1589-1600.

21. Dalgliesh W.A. Comparison of model/full-scale wind pressures on a high-rise building. Journal of Industrial Aerodynamics 1 (1975) 55-66.

22. Dalgliesh W.A., Cooper K.R., Templin J.T. Comparison of model and full-scale accelerations of a high-rise building. Journal of Wind Engineering and Industrial Aerodynamics 13 (1983) 217-228.

23. Davenport A.G. Rationale for determining design wind velocities. ASCE Journal of the Structural Division 86(5) (1960) 39-68.

24. Davenport A.G. The relationship of wind structure to wind loading. Proc. 1st Conference on Wind Effects on Building and Structures, National Physical Laboratory, Teddington, England, 1965, 53-102.

25. Domínguez D., Gonzalo J., López D. A wind speed profile measurement method based on free bubble tracking in the lower atmosphere. Flow Measurement and Instrumentation 34 (2013) 134-141.

26. Elsharawy M., Galal K., Stathopoulos T. Torsional and shear wind loads on flat-roofed buildings. Engineering Structures 84 (2015) 313-324. 
27. Endo M., Bienkiewicz B., Ham H.J. Wind-tunnel investigation of point pressure on TTU test building. Journal of Wind Engineering and Industrial Aerodynamics 94(7) (2006) 553-578.

28. Eurocode 1: Actions on structures - Part 1-4: General actions - Wind actions. (polish version: PN-EN 1991-1-4). PKN, Warsaw, 2008.

29. Franke, J., Hellsten, A., Schlünzen, H., Carissimo, B. (Eds.). Best practice guideline for the CFD simulation of flows in the urban environment. COST Office Brussels, 2007.

30. Franke, J., Hellsten, A., Schlünzen, H., Carissimo, B. The COST 732 best practice guideline for CFD simulation of flows in the urban environment - A summary. International Journal of Environmental Pollution 44(1-4) (2011) 419-427.

31. Fu J.Y., Wu J.R., Xu A., Li Q.S., Xiao Y.Q. Full-scale measurements of wind effects on Guangzhou West Tower. Engineering Structures 35 (2012) 120-139.

32. Goliger A.M., Milford R.V. Sensitivity of the CAARC standard building model to geometric scale and turbulence. Journal of Wind Engineering and Industrial Aerodynamics 31(1) (1988) $105-123$.

33. Gonzalo J., Domínguez D., López D., Fernández J. Lighter-than-air particle velocimetry for wind speed profile measurement. Renewable and Sustainable Energy Reviews 33 (2014) 323-332.

34. Guo Y.L., Kareem A., Ni Y.Q., Liao W.Y. Performance evaluation of Canton Tower under winds based on full-scale data. Journal of Wind Engineering and Industrial Aerodynamics 104-106 (2012) 116-128.

35. Habte F., Mooneghi M.A, Chowdhury A.G., Irwin P. Full-scale testing to evaluate the performance of standing seam metal roofs under simulated wind loading. Engineering Structures 105(15) (2015) 231-248.

36. He Y.C., Chan P.W., Li Q.C. Wind characteristics over different terrains. Journal of Wind Engineering and Industrial Aerodynamics 120 (2013) 51-69.

37. Hu G., Tse K.T., Kwok K.C.S., Zhang Y. Large eddy simulation of flow around an inclined finite square cylinder. Journal of Wind Engineering and Industrial Aerodynamics 146 (2015) 172-184.

38. Huang S.H., Li Q.S., Xu S. Numerical evaluation of wind effects on a tall steel building by CFD. Journal of Constructional Steel Research 63 (2007) 612-627.

39. ISO 4354:2009. Wind actions on structures. ISO, 2009.

40. Jin Z., Dong Q., Yang Z. A stereoscopic PIV study of the effect of rime ice on the vortex structures in the wake of a wind turbine. Journal of Wind Engineering and Industrial Aerodynamics 134 (2014) 139-148.

41. Kim J.H., Han Y.O. Experimental investigation of wake structure around an external rear view mirror of a passenger car. Journal of Wind Engineering and Industrial Aerodynamics 99 (2011) 1197-1206.

42. Kim W., Tamura Y., Yoshida A. Interference effects on aerodynamic wind forces between two buildings. Journal of Wind Engineering and Industrial Aerodynamics 147 (2015) 186-201.

43. Letchford C.W., Lander D.C., Case P., Dyson A., Amitay M. Bio-mimicry inspired tall buildings: The response of cactus-like buildings to wind action at Reynolds Number of $10^{4}$. Journal of Wind Engineering and Industrial Aerodynamics 150 (2016) 22-30.

44. Li Q.S., Wu J.R. Time-frequency analysis of typhoon effects on a 79-storey tall building. Journal of Wind Engineering and Industrial Aerodynamics 95 (2007) 1648-1666.

45. Li Q.S., Xiao Y.Q., Wong C.K. Full-scale monitoring of typhoon effects on super tall buildings. Journal of Fluids and Structures 20 (2005) 697-717.

46. Li Q.S., Xiao Y.Q., Wu J.R., Fu J.Y., Li Z.N. Typhoon effects on super-tall buildings. Journal of Sound and Vibration 313 (2008) 581-602.

47. Li Q.S., Zhi L., Hu F. Boundary layer wind structure from observations on a $325 \mathrm{~m}$ tower. Journal of Wind Engineering and Industrial Aerodynamics 98 (2010) 818-832.

48. Lipecki T. Relationship between wind pressure on surface of rectangular prisms and atmospheric boundary layer parameters. Technical Transactions 12(2-B) (2015) 91-105.

49. Lipecki T., Jamińska P. Influence of wind structure and aspect ratio of circular cylinders on mean wind pressure coefficient. TASK QUARTERLY 16(3-4) (2012) 203-218. 
50. Melbourne W.H. Comparison of measurements on the CAARC standard tall building model in simulated model wind flows. Journal of Wind Engineering and Industrial Aerodynamics 6(1-2) (1980) 73-88.

51. Oguma Y., Yamagata T., Fujisawa N. Measurement of sound source distribution around a circular cylinder in a uniform flow by combined particle image velocimetry and microphone technique. Journal of Wind Engineering and Industrial Aerodynamics 118 (2013) 1-11.

52. Ozmen Y., Baydar E., van Beeck J.P.A.J. Wind flow over the low-rise building models with gabled roofs having different pitch angles. Building and Environment 95 (2016) 63-74.

53. Pozzuoli C., Bartoli G., Peil U., Clobes M. Serviceability wind risk assessment of tall buildings including aeroelastic effects. Journal of Wind Engineering and Industrial Aerodynamics 123 (2013) 325-338.

54. Refan M., Hangan H. Characterization of tornado-like flow fields in a new model scale wind testing chamber. Journal of Wind Engineering and Industrial Aerodynamics 151 (2016) 107-121.

55. Refan M., Hangan H., Wurman J. Reproducing tornadoes in laboratory using proper scaling. Journal of Wind Engineering and Industrial Aerodynamics 135 (2014) 136-148.

56. Richards P.J., Hoxey R.P. Pressures on a cubic building: Part 1. Full-scale results. Journal of Wind Engineering and Industrial Aerodynamics 102 (2012) 72-86.

57. Richards P.J., Hoxey R.P. Wind loads on the roof of a $6 \mathrm{~m}$ cube. Journal of Wind Engineering and Industrial Aerodynamics 96 (2008) 984-993.

58. Richardson G.M., Hoxey R.P., Robertson A.P., Short J.L. The Silsoe Structures Building: Comparisons of pressures measured at full scale and in two wind tunnels. Journal of Wind Engineering and Industrial Aerodynamics 72 (1997) 187-197.

59. Rizzo F. Wind tunnel tests on hyperbolic paraboloid roofs with elliptical plane shapes. Engineering Structures 45 (2012) 536-558.

60. Roth M. Review of atmospheric turbulence over cities. Quarterly Journal of the Royal Meteorological Society 126 (2000) 941-990.

61. Šarkić A., Höffer R., Brčić S. Numerical simulations and experimental validations of force coefficients and flutter derivatives of a bridge deck. Journal of Wind Engineering and Industrial Aerodynamics 144 (2015) 172-182.

62. Shiau B.S., Chen B.Y. Observation on wind turbulence characteristics and velocity spectra near the ground at the coastal region. Journal of Wind Engineering and Industrial Aerodynamics 90 (2002) 1671-1681.

63. Tamura Y., Iwatani Y., Hibi K., Suda K., Nakamura O., Maruyama T., Ishibashi R. Profiles of mean wind speeds and vertical turbulence intensities measured at sea shore and two in land sites using Doppler sodars. Journal of Wind Engineering and Industrial Aerodynamics 95 (2007) 411-427.

64. Tamura Y., Suda K., Sasaki A., Miyashita K., Iwatani Y., Maruyama T., Hibi K., Ishibash R. Simultaneous wind measurements over two sites using Doppler sodars. Journal of Wind Engineering and Industrial Aerodynamics 89 (2001) 1647-1656.

65. Tamura, T., Nozawa, K., Kondo, K. AIJ guide for numerical prediction of wind loads on buildings. Journal of Wind Engineering and Industrial Aerodynamics, 96 (10-11) (2008) 19741984.

66. Taylor Z.J., Gurka R., Kopp G.A. Effects of leading edge geometry on the vortex shedding frequency of an elongated bluff body at high Reynolds numbers. Journal of Wind Engineering and Industrial Aerodynamics 128 (2014) 66-75.

67. Tieleman H.W. Strong wind observations in the atmospheric surface layer. Journal of Wind Engineering and Industrial Aerodynamics 96 (2008) 41-77.

68. Tominaga, Y., Mochida, A., Yoshie, R., Kataoka, H., Nozu, T., Yoshikawa, M., Shirasawa, T. AIJ guidelines for practical applications of CFD to pedestrian wind environment around buildings. Journal of Wind Engineering and Industrial Aerodynamics 96(10-11) (2008) 1749-1761.

69. Yi. J, Li Q.S. Wind tunnel and full-scale study of wind effects on a super-tall building. Journal of Fluids and Structures 58 (2015) 236-253. 
70. Yoshie, R., Mochida, A., Tominaga, Y., Kataoka, H., Harimoto, K., Nozu, T., Shirasawa, T. Cooperative project for CFD prediction of pedestrian wind environment in the Architectural Institute of Japan. Journal of Wind Engineering and Industrial Aerodynamics, 95(9-11) (2007) 1551-1578.

\section{Zagadnienia współczesnej inżynierii wiatrowej i aerodynamiki budowli}

\section{Tomasz Lipecki, Paulina Jamińska}

Katedra Mechaniki Budowli, Wydziat Budownictwa i Architektury, Politechnika Lubelska, e-mail: t.lipecki@pollub.pl,p.jaminska@pollub.pl

Streszczenie: W artykule opisane zostały aktualne zagadnienia, jakimi zajmuje się inżynieria wiatrowa i aerodynamika budowli. Skoncentrowano się głównie na aspektach związanych z aerodynamiką budowli. W pracy krótko przedstawiono podstawy teoretyczne, które należy uwzględnić przy przyjmowaniu obciążenia wiatrem. Następnie opisano trzy różne instrumenty badawcze służące do opisu obciążenia wiatrem: badania w skali rzeczywistej, badania w tunelach aerodynamicznych oraz symulacje komputerowe. Na zakończenie dokonano przeglądu aktualnych problemów podejmowanych przez inżynierię wiatrową.

Słowa kluczowe: inżynieria wiatrowa, aerodynamika, badania $\mathrm{w}$ tunelach aerodynamicznych, Obliczeniowa Mechanika Płynów, badania w skali rzeczywistej. 
